\title{
Triple oxygen isotope constraints on \\ the nature of missing late veneer from Archean ultramafic rocks
}

STEFAN T.M. PETERS ${ }^{1}$, MEIKE B. FISCHER ${ }^{1}$, ANDREAS PACK $^{1}$ AND KRISTOFFER SZILAS ${ }^{2}$

${ }^{1}$ University of Göttingen

${ }^{2}$ University of Copenhagen

Presenting Author: s.peters@geo.uni-goettingen.de

Ultramafic enclaves in the crust of the Eoarchean Itsaq Gneiss Complex and Mesoarchean Fiskefjord region of southwest Greenland carry a uniform excess in s-process Ru compared to the bulk silicate Earth [1]. The s-process $\mathrm{Ru}$ excess is explained by a deficit in late accreted materials that carried a deficit in sprocess $\mathrm{Ru}$. It was suggested that the missing late veneer component resembles carbonaceous chondrite-like materials with up to $0.3 \%$ the mass of the Earth, and a missing CM chondritelike component was favoured [1]. This suggestion provides impetus to study the triple oxygen isotope compositions of the ultramafic enclaves, because most carbonaceous chondrite groups have several thousands of ppm lower $\Delta^{, 17} \mathrm{O}$ values than the bulk silicate Earth [2]. We found that the $\Delta^{, 17} \mathrm{O}$ values of pristine olivine from the ultramafic enclaves are identical to olivine $\Delta^{17} \mathrm{O}$ values in post-Archean mantle peridotite, at the level of $<2 \mathrm{ppm}$. We show that not more than $<0.17$ oxygen at.\% CM-chondrite like materials can therefore be missing from the ultramafic enclaves. A missing late veneer component that would resemble most other carbonaceous chondrite groups is restricted at the level of ca. $<0.15$ oxygen at. $\%$ as well, with the exception of CI chondrites, for which a larger missing component $(<1.9$ oxygen at.\%) is possible. If the missing late veneer component from the ultramafic enclaves resembles $\mathrm{CM}$ chondrites, it is therefore either small $(<0.17 \%$ the mass of the Earth; based on [3]) or, alternatively, its $\mathrm{O} / \mathrm{Ru}$ ratio became fractionated such that the $\mathrm{Ru}$ isotope composition, but not the oxygen isotope composition of the pre-late veneer mantle was preserved in the Itsaq Gneiss Complex and Fiskefjord mantle. As a third possibility, we suggest that the missing late veneer component could resemble CI chondrites.

[1] Fisher-Gödde et al. 2020 Nature 579 240-244. [2] Clayton, 1993 Annu Rev Earth Planet Sci 21.1 115-149 [3] Palme and O’Neill 2003, Treatise on Geochemistry 2568 